\title{
Plant protein from grains to partially replace meat in the human diet
}

\author{
S. Multari ${ }^{1}$, M. Neacsu ${ }^{1}$, N.J. Vaughan ${ }^{1}$, G. Duncan ${ }^{1}$, D. Stewart ${ }^{2}$ and W.R. Russell ${ }^{1}$ \\ ${ }^{1}$ Rowett Institute of Nutrition and Health, University of Aberdeen, AB21 9SB, UK and ${ }^{2}$ The James Hutton Institute, \\ Invergowrie, Dundee DD2 5DA, UK
}

Food security is an issue of high concern as it impacts on the lives of millions of people worldwide, especially the most vulnerable communities. Also, with the rapid growth in the world's population, food security has been seen as a significant challenge for the agrifood industry and policy makers, as it is strictly interlinked with climate change. ${ }^{(1)}$ The aim of this research project is to provide food that will feed an increasing unhealthy population.

To date, the research has demonstrated that there are high-protein crops, which can be grown sustainably in the UK that could provide a healthy alternative to partially replace our dependency on unsustainable protein-rich foodstuffs. This includes meat, the production of which is responsible for a substantial share of food-related environmental pressures. ${ }^{(2)}$ Selected crops: green pea, lupin, fava bean, hemp and buckwheat, were analysed for their macro- and micro- nutrient content, as well as their phytochemical profile. The crops studied were found to contain a diverse range of phenolic compounds, including phenolic acids and their derivatives and several classes of flavonoids. As fava bean contained relatively high amount of protein $(22 \% \mathrm{w} / \mathrm{w})$, protein fractions were isolated and further investigated to understand the contribution of the phytochemical components in terms of protein functionality, stability and oxidation. Since fava bean protein isolates showed promising food applications, they were used to develop meat patties. Increasing the amount of fava bean protein, significantly decreased lipid oxidation $(r=0.885 ; \mathrm{P}<0.001)$, as shown by an increase in induction time (Fig. 1a), and protein oxidation $(\mathrm{r}=-0.949 ; \mathrm{P}<0.001)$, as shown by a decrease in the concentration of carbonyl groups produced per gram of protein (Fig. 1b).
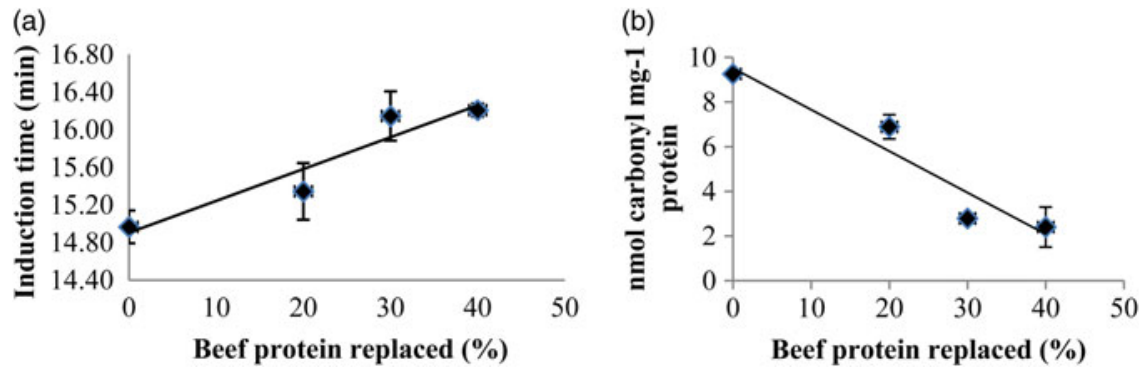

Fig. 1. Effect of replacing, in meat patties, meat protein with fava bean protein isolates on lipid oxidation (Fig. 1a), as measured by the Rancimat method. ${ }^{(3)}$, and on protein oxidation (Fig. 1b), as measured by protein carbonyl group determination ${ }^{(4)}$. All the analysis were performed in triplicate and data were analysed by IBM SPSS Statistics.

The results of this research could encourage a higher consumption of plant-based products, which would be favourable from both a health and environmental perspective.

(1) Day L (2013) Trends Food Sci Technol 32, 25-42.

(2) de Boer J \& Aiking H (2011) Ecol Econ 70, 1259-1265.

(3) Duthie G, Campbell F, Bestwick C et al. (2013) Nutrients 5, 1241-1252.

(4) Vuorela S, Salminen H, Makela M et al. (2005) J Agric Food Chem 53, 8492-8497. 